\title{
Diabetes and macrovasculopthy: Double trouble!
}

\author{
Sayeeda Rahman \\ Lecturer, Department of Clinical Sciences, School of Medical Sciences, University of Bradford, West Yorkshire, Bradford, UK. \\ Associate Editor, South East Asia Journal of Public Health, Bangladesh.
}

Diabetes is a chronic, degenerative, and noncommunicable disease associated with a high prevalence of cardiovascular morbidity and mortality. 1,2 The most recent estimates of the International Diabetes Federation (IDF) indicate that $8.3 \%$ of adults i.e. 382 million people have diabetes, and the number of people with the disease is set to rise beyond 592 million in less than 25 years. ${ }^{3}$ It is worrying that 175 million of cases currently unaware of their diagnosis and progressing towards complications. Moreover, with $80 \%$ of the total number affected living in low- and middle-income countries, where the epidemic is gathering pace at alarming rates.

According to IDF, approximately one-fifth of all adults with type 2 diabetes mellitus (T2DM) in the world live in the South-East Asia Region. ${ }^{3}$ Current estimates indicate that $8.2 \%$ of the adult population, or 72.1 million people, have diabetes, 65.1 million of whom live in India. IDF also forecasted that the number of people with $\mathrm{T} 2 \mathrm{DM}$ in the region will increase to 123 million by 2035 , or $8.2 \%$ of the adult population. A further 24.3 million people have impaired glucose tolerance (IGT), and this will increase to 38.8 million by 2035. The number of people with T2DM in India, Bangladesh and Sri Lanka make up $98.8 \%$ of the total for the region. A recent systematic review and metaanalysis conducted by Jayawardena et $a l .{ }^{4}$ on prevalence and trends of the diabetes epidemic in South Asia highlighted that urban populations had a higher prevalence of diabetes. Moreover, an increasing trend in prevalence of diabetes was observed in urban/rural India and rural Sri Lanka. A high epidemicity index was seen in Sri Lanka (52.8\%), while for other countries, the epidemicity index was comparatively low (rural India: $26.9 \%$; urban India: $31.3 \%$ and urban Bangladesh: 33.1\%). It was also found that family history, urban residency, age, higher BMI, sedentary lifestyle, hypertension and waisthip ratio were associated with increased risks of T2DM.

A sharp increase in the prevalence of T2DM has been observed in the SEA Region, both in urban and rural areas, which is mostly associated with lifestyles, highfat diets and decreased exercise. ${ }^{6}$ T2DM is the leading cause of CVD, renal disease, blindness and amputation. ${ }^{1,3}$ Cardiovascular disease (CVD) is a major complication and the leading cause of early death among people with T2DM. ${ }^{1}$ About $65 \%$ of people with T2DM die from heart disease and stroke. Adults with T2DM are 2-4 times more likely to have heart diseases or suffer a stroke than people without T2DM. High blood glucose in adults with T2DM increases the risk of heart attack, stroke, angina, and coronary artery disease. The clustering of vascular risk led to the view that $\mathrm{CV}$ risk appears early, prior to the development of T2DM.,6-9 Progressive nature of both T2DM and associated CV risk poses specific challenges at different stages of the life of an individual with T2DM. ${ }^{1}$

The complications of diabetic vasculopathy are commonly grouped into microvascular and macrovascular complications. ${ }^{2}$ In diabetes, macrovascular complications are the commonest cause of morbidity and mortality and are responsible for a high incidence of vascular diseases. ${ }^{1}$ Macrovascular diseases are traditionally thought of as due to underlying obstructive atherosclerotic diseases affecting major arteries. ${ }^{2}$ The following pathological changes of major blood vessels occur which lead to functional and structural abnormalities in diabetic vessels include endothelial dysfunction, reduced vascular compliance and atherosclerosis. ${ }^{2}$ Besides, advanced glycation end product formation interacts with specific receptors that lead to overexpression of a range of cytokines. Haemodynamic pathways are activated in diabetes and are possibly amplified by concomitant systemic hypertension. Apart from these, hyperglycaemia, non-enzymatic glycosylation, lipid modulation, alteration of vasculature and growth factors activation contribute to development of diabetic vasculopathy. This review focuses on pathophysiology and pathogenesis of diabetes-associated macrovasculopathy. Studies also demonstrated that following patient groups develop early manifestations of preclinical macrovasculopathy: newly diagnosed, never-treated individuals with T2DM/IGT and no traditional CV risk factors, and normoglycemic and normotensive offspring of parents with T2DM/IGT. ${ }^{6-9}$ The presence of diabetes in parents constitutes increased risk of earlier onset of disease and its CVD complications in their offspring. ${ }^{9}$ The studies on arterial stiffness in young people and offspring of diabetic parents are scarce, and limited study was reported in the literature on the offspring of patients with IGT. ${ }^{9}$

The modalities of treatment of diabetes includes: lifestyle modification (appropriate diet and exercise programs) and pharmacological intervention. Effective management of following reduce $\mathrm{CV}$ risks in diabetic patients: blood glucose, hypertension, blood lipid and blood hypercoagulability. ${ }^{1}$

Correspondence: Dr. Sayeeda Rahman, Lecturer, Department of Clinical Sciences, School of Medical Sciences, University of Bradford, Bradford BD7 1DP, West Yorkshire, UK. E-mail: srahman6@bradford.ac.uk. 
Increased obesity and decreased physical activity are strongly linked with an increased prevalence and incidence of T2DM. ${ }^{3}$ Obesity is a predictor of both coronary heart disease and T2DM. ${ }^{1}$ About $80 \%-90 \%$ of $\mathrm{DM}$ is attributable to excess weight. Limited studies conducted to assess the effect of intensive lifestyle intervention on $\mathrm{CV}$ outcome in T2DM. ${ }^{1}$ Look AHEAD (Action for Health in Diabetes) study demonstrated that weight loss did not reduce the rate of CV events in overweight or obese adults with DM. ${ }^{10}$

Prolonged hyperglycaemia is a major factor in the pathogenesis of diabetic vasculopathy. ${ }^{1,2}$ Observational studies $^{11,12}$ found positive correlations between measures of glycaemic control and CV outcomes; however, clinical trials ${ }^{13-16}$ failed to show consistent beneficial effects on cardiovascular events. It was demonstrated that glycaemic control reduces the risk of microvascular complications among patients with DM, but its effect on CVD is uncertain. ${ }^{17-19}$ Though the landmark UKPDS $34^{13}$ showed protective effect on CVD, CV mortality, and all-cause mortality in T2DM patients, the large randomized, controlled trials ${ }^{14,16,22}$ found conflicting results.

Patients with T2DM and blood pressure (BP) are always at increased risk of morbidity and mortality from $\mathrm{CV}$ events. ${ }^{1}$ Diabetic macrovasculopathy can be improved by lowering BP with antihypertensive drugs. Though a number of randomized controlled trials showed adequate aggressive $\mathrm{BP}$ control improves $\mathrm{CV}$ outcomes, ${ }^{20-21}$ but others ${ }^{16}$ found no positive results.

Dyslipidemia also contributes substantially to $\mathrm{CV}$ complications in patients with T2DM. ${ }^{1}$ A number of studies have shown that lowering LDL cholesterol reduces the risk of major vascular events diabetic patients. Randomized controlled trials ${ }^{23}$ in T2DM have consistently shown that statins significantly reduce the risk of major primary and secondary $\mathrm{CV}$ endpoints but trials $^{24-26}$ of fibrate therapy have shown mixed results.

Atherosclerosis and vascular thrombosis are major contributors to diabetic vasculopathy. ${ }^{1}$ Platelets play a significant role in increasing the risk of CVD. Currently, aspirin is at the centre of this research and is widely recommended for primary prevention of $\mathrm{CV}$ events. Major guidelines ${ }^{27}$ recommended aspirin for primary prevention of $\mathrm{CV}$ events, however a number of trials ${ }^{28-30}$ found that aspirin did not prevent a first cardiovascular event or death and recommended to continue aspirin for secondary prevention. However, other antiplatelet drugs (e.g. Clopidogrel) were also found to reduce the risk of $\mathrm{CV}$ events in DM patients. ${ }^{31.32}$

There are a number of research gaps in the area of diabetes and macrovasculopathy which creates opportunities for the scientist/researchers to conduct clinical trials: (i) lifestyle: effect of exercise and diet on quality of life, morbidity, and mortality, with a special focus on CV outcomes, (ii) glycaemic control: effective pharmacological approaches for the management of hyperglycemia which also affect CVD risk reduction, (iii) blood pressure: aggressive BP control may be the most important factor in preventing adverse $\mathrm{CV}$ outcomes, (iv) lipid profiles: routine use of combination therapy with fibrate and statin to reduce $\mathrm{CV}$ risk as compared with statin alone, and (v) antiplatelet therapy: clear benefit of aspirin in the primary prevention of major CV events in T2DM patients.

Diabetes mellitus has reached epidemic proportions worldwide. South Asians are known to have an increased predisposition for diabetes which has become an important health concern in the region. ${ }^{5}$ It is evident that several modifiable and non-modifiable risk factors play an important role in the pathogenesis of diabetes among South Asians. Hence there is an urgent need for more research to develop preventive and curative strategies to prevent diabetic epidemic in the region. The relationship of various degrees of glucose intolerance and CVD required to be investigated by longitudinal studies in different ethnic groups.

\section{References}

1. Rahman S, Rahman ARA. Treatment of Diabetic Vasculopathy: An Overview. Res Rep Endocr Disord 2011;1:21-36

2. Rahman S, Rahman T, Ismail AA, Rashid AR. Diabetes-associated macrovasculopathy: pathophysiology and pathogenesis. Diabetes Obes Metab 2007;9(6):767-80.

3. International Diabetes Federation (IDF). Diabetes Atlas. $6^{\text {th }}$ ed. Brussels: International Diabetes Federation, 2013.

4. Jayawardena R, Ranasinghe P, Byrne NM, Soares MJ, Katulanda P, Hills AP. Prevalence and trends of the diabetes epidemic in South Asia: a systematic review and meta-analysis. BMC Public Health 2012;12:380.

5. Ramachandran A, Snehalatha C, Ma RC. Diabetes in South-East Asia: an update. Diabetes Res Clin Pract.2014;103(2):231-7.

6. Rahman S, Ismail AA, Rahman AR. Treatment of diabetic vasculopathy with rosiglitazone and ramipril: Hype or hope? Int J Diabetes Dev Ctries 2009;29(3):110-7.

7. Rahman S, Ismail AA, Ismail SB, Naing NN, Rahman AR. Early manifestation of macrovasculopathy in newly diagnosed never treated type II diabetic patients with no traditional CVD risk factors. Diabetes Res Clin Pract 2008;80(2):253-8.

8. Rahman S1, Ismail AA, Ismail SB, Naing NN, Abdul Rahman AR. Effect of Rosiglitazone and Ramipril on Preclinical Vasculopathy in Newly Diagnosed, Untreated T2DM and IGT Patients: One-year Randomised, Double-blind and Placebo-controlled Study. Eur J Clin Pharmacol 2007;63(8):733-41.

9. Rahman S, Ismail AA, Ismail SB, Naing NN, Rahman AR. Increased arterial stiffness in 
normoglycaemic offspring of newly diagnosed, never treated type 2 diabetic and impaired glucose tolerance parents. $\mathrm{Br} J$ Diabetes Vasc Dis 2009;9:65-8.

10. The Look AHEAD Research Group. Cardiovascular Effects of Intensive Lifestyle Intervention in Type 2 Diabetes. N Engl J Med 2013;369 (2):145-54

11. Khaw KT, Wareham N, Luben R, et al. Glycated haemoglobin, diabetes, and mortality in men in Norfolk cohort of European prospective investigation of cancer and nutrition (EPICNorfolk). BMJ 2001; 322(7277):15-8.

12. Stratton IM, Adler AI, Neil HA, et al. Association of glycaemia with macrovascular and microvascular complications of type 2 diabetes (UKPDS 35): prospective observational study. BMJ 2000;321(7258):405-12.

13. UK Prospective Diabetes Study (UKPDS) Group. Effect of intensive blood-glucose control with metformin on complications in overweight patients with type 2 diabetes (UKPDS 34). Lancet 1998;352(9131):854-65.

14. Patel A, MacMahon S, Chalmers J, et al. Intensive blood glucose control and vascular outcomes in patients with type 2 diabetes. $N$ Engl J Med 2008;358(24):2560-72.

15. Schor S. The University Group Diabetes Program. A statistician looks at the mortality results. JAMA 1971;217(12):1671-5.

16. Action to Control Cardiovascular Risk in Diabetes Study Group. Effects of intensive glucose lowering in type 2 diabetes. $N$ Engl J Med 2008;358(24):2545-59.

17. UK Prospective Diabetes Study (UKPDS) Group. Intensive blood glucose control with sulphonylureas or insulin compared with conventional treatment and risk of complications in patients with type 2 diabetes (UKPDS 33). Lancet 1998;352(9131):837-53.

18. Shichiri M, Kishikawa H, Ohkubo Y, Wake N. Long-term results of the Kumamoto Study on optimal diabetes control in type 2 diabetic patients. Diabetes Care 2000;23 Suppl 2:B21-B29.

19. Holman RR, Paul SK, Bethel MA, Matthews DR, Neil HA. 10-year follow-up of intensive glucose control in type 2 diabetes. $N$ Engl J Med 2008;359(15):1577-89.

20. Hansson L, Zanchetti A, Carruthers SG, et al. Effects of intensive blood pressure lowering and low-dose aspirin in patients with hypertension: principal results of the Hypertension Optimal Treatment (HOT) randomised trial. HOT Study Group. Lancet 1998;351(9118):1755-62.

21. UK Prospective Diabetes Study Group. Tight blood pressure control and risk of macrovascular and microvascular complications in type 2 diabetes: UKPDS 38. BMJ 1998;317(7160):703-13.
22. Nathan DM. Navigating the choices for diabetes prevention. N Engl J Med 2010;362(16):1533-5.

23. Cholesterol Treatment Trialists' (CTT) Collaborators. Efficacy of cholesterol-lowering therapy in 18,686 people with diabetes in 14 randomized trials of statins: a meta-analysis. Lancet 2008;371(9607):117-25.

24. Koskinen P, Manttari M, Manninen V, Huttunen JK, Heinonen OP, Frick MH. Coronary heart disease incidence in NIDDM patients in the Helsinki Heart Study. Diabetes Care 1992;15 (7):820-25.

25. Rubins HB, Robins SJ, Collins D, et al; VA-HIT Study Group. Diabetes, plasma insulin, and cardiovascular disease subgroup analysis from the Department of Veterans Affairs high-density lipoprotein intervention trial (VA-HIT). Arch Intern Med 2002;162(22):2597-604.

26. Keech A, Simes RJ, Barter P, et al. Effects of long-term fenofibrate therapy on cardiovascular events in 9795 people with type 2 diabetes mellitus (the FIELD study): randomised controlled trial. Lancet 2005;366(9500):1849-61.

27. Rydén L, Standl E, Bartnik M, et al. Guidelines on diabetes, pre-diabetes, and cardiovascular diseases: executive summary. The Task Force on Diabetes and cardiovascular Diseases of the European Society of Cardiology (ESC) and of the European Association for the Study of Diabetes (EASD). Eur Heart J 2007;28(1):88-136.

28. Belch J, MacCuish A, Campbell I, et al. The prevention of progression of arterial disease and diabetes (POPADAD) trial: factorial randomised placebo controlled trial of aspirin and antioxidants in patients with diabetes and asymptomatic peripheral arterial disease. $B M J$ 2008; 337:a1840.

29. Ogawa H, Nakayama M, Morimoto $\mathrm{T}$, et al; Japanese Primary Prevention of Atherosclerosis With Aspirin for Diabetes (JPAD) Trial Investigators. Low-dose aspirin for primary prevention of atherosclerotic events in patients with type 2 diabetes: a randomized controlled trial. JAMA 2008;300(18):2134-41.

30. De Berardis G, Sacco M, Strippoli GF, et al. Aspirin for primary prevention of cardiovascular events in people with diabetes: meta-analysis of randomised controlled trials. BMJ 2009;339:b4531.

31. Bhatt DL, Marso SP, Hirsch AT, et al. Amplified benefit of clopidogrel versus aspirin in patients with diabetes mellitus. Am J Cardiol 2002;90 (6):625-8.

32. Roffi M, Chew DP, Mukherjee D, et al. Platelet glycoprotein IIb/IIIa inhibitors reduce mortality in diabetic patients with non-ST-segment e levation acute coronary syndromes. Circulation. 2001;104(23): 2767-71. 